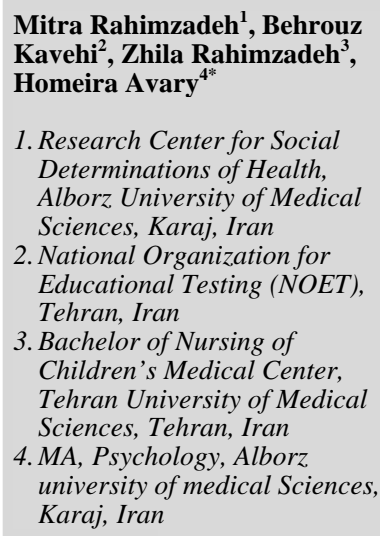

1. Research Center for Social Determinations of Health, Alborz University of Medical Sciences, Karaj, Iran

2. National Organization for Educational Testing (NOET) Tehran, Iran

3. Bachelor of Nursing of Children's Medical Center, Tehran University of Medical Sciences, Tehran, Iran

4. MA, Psychology, Alborz university of medical Sciences, Karaj, Iran

*Corresponding Author: MA, Psychology, Alborz university of medical Sciences, Karaj, Iran

Tel: 026-34588414

E-mail: homeiraavary@yahoo.com

\section{Prevalence of Depression in Diabetic Patients: Article Review and Meta-Analysis}

Received: 31 Jan. 2017 ; Accepted: 18 Aug. 2017

\section{Abstract}

Background: Diabetes and depression are among diseases highly associated with life style, urbanism, and industrialization. The concomitance of the two of them costs the patients many years of their lives. Many researchers have been done on the outbreak of depression among diabetics in Iran. The principal purpose of this study is to determine the outbreak of depression among diabetics using the Meta-analysis method.

Methods: This study is a systematic review. The prevalence rate of depression among diabetics estimation was determined using Meta-analysis method on the data extracted from English and Persian data bases. To analyze the information obtained, we used STATA 11.2 and the random effect model.

Results: Among 32 eligible researches 7135 patients with type I and II diabetes were chosen for this study. Using Beck's self-report scale $65 \%$ of the cases shown mild to severe symptoms of depression. $64 \%$ of the patients were female and the prevalence rate of depression was reported $71.3 \%$ in the female and $60.3 \%$ in the male cases.

Conclusion: The prevalence rate of depression among Iranian diabetics is higher in comparison with other countries. Considering the fact that the concomitance of the two of these diseases results in a raise in medical costs, it is recommended to the doctors to check for depression symptoms in diabetics and recommend health solutions to the patient and the one accompanying them.

Keywords: Prevalence of depression, Diabetics, Systematic review, Meta-analysis 


\section{شيوع افسردَى در بيماران ديابتيك (يك مطالعه نظاممند و فرا تحليل)}

تاريخ دريافت مقاله:9Q/11/1Y

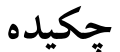

زمينه: ديابت و افسردگى ازجمله بيمارىهايى هستند كه به دليل شيوه زندگى، شهرنشينى و صنعتى شدن در همـه جوامـع شيوع بالايى دارند. همر اهى اين دو بيمارى مزمن باهم موجب از دست رفتن سالهاى زيادى از عمـر مسىشـود. مطالعـات زيادى در رابطه با شيوع افسردگى در بيماران ديابتيك در ايران انجامشده است. هدف از اين مطالعه تعيين شيوع افسـردگى در بيماران ديابتيك به روش فرا تحليل مىباشد. روشها: مطالعه حاضر يك مطالعه مرور نظام مند است. برآورد شيوع افسردگى در بيماران ديابتيك به روش فرا تحليـل از بين مطالعاتى كه از طريق جستجو در يايڤاههاى اطلاعاتى فارسىزبان و انخليسىزبان به دست آمل، محاسبه گرديــ. بـراى تجزيهوتحليل اطلاعات بهدستآمده نرمافزار 11.2 STATA و مدل اثرات تصادفى استفاده گرديد. يافته ها: از بين بس مطالعه واجد شرايط تعداد هrاV بيمار ديابتيك نوع يكى و دو مورد بررسى قـرار كرفـت. بـا اسـتفاده از معيار خودگزارش دهى بكى هو درصد از بيماران ديابتيك نشانهاييى از افسردگى خفيف تا شديد را دارا بودند. باو درصـد از شركت كنندگان زن بودند و شيوع افسردكى در زنان س/ ال درصد و در مردان س/ • نتيجه گيرى: شيوع افسردگى در بيماران ديابتيك در ايران بالاتر از ديخر كشورهاست و با توجه به اين موضوع كه همراهـى اين دو بيمارى باهم موجب افزايش هزينهاى درمان مىشود، توصيه مىشود در مراجعه بيماران براى درمان بيمارى ديابت به نشانههاى بيمارى افسردگى نيز توجه شده و توصيههاى كمكى به بيمار و همراه او براى كاهش علائم افسردگى صورت يذّيرد.

كلمات كليدى: شيوع افسردگى، بيماران ديابتيك، مرور نظام مند، فرا تحليل

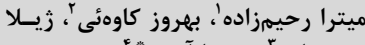

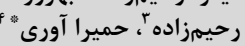

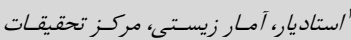

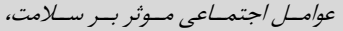

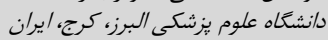

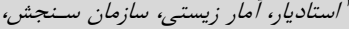
تمهران، ايران

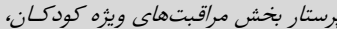

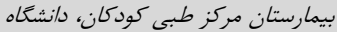

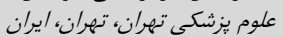

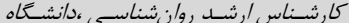
علوم يزشكى البرز، كرج ،ايران 
مبتلابه ديابت هستند." "در مطالعه مرورى كه توسط حـقدوسـت و

همكاران انجام گرفت، شيوع ديابت در جمعيت بـالاى ·F سـال

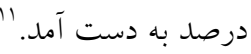
افسردكى عارضه روحى اسـت كـه شـيوع بـالايى در دنيـا دارد

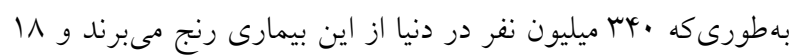

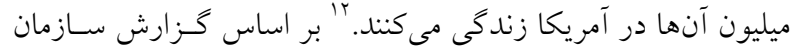

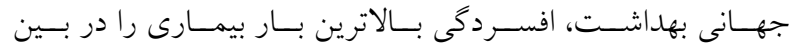
بيمارىهاى غير كشنده دارد بهطورىكه با درصــ از عمــر افـراد بـا

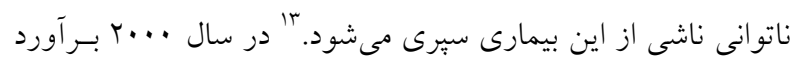

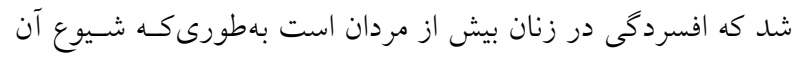
در هر صد هزار زن •بوع تخمين زده شد درحسالىكسه شسيوع آن در هر صد هزار مرد 99 اسب به دست آمد. افسردگى در جهان جهـارمين بار بيمارى در زنان و هفتمين بار بيمارى در مردان است.

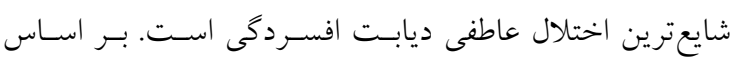
مطالعهاى كه در سال IrVDI در مركز تحقيقات اصـفهان انجـام شـد،

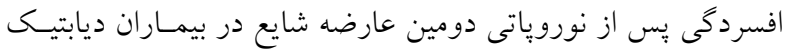
مىباشد. افسردگى با تغيير در شيوهى زندگى يـك بيمـار مبـتلا بـهـ

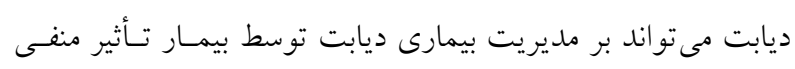
بحزارد.

بهوروكلى تأثيرات منفى افسردكى در بيماران مبـتلا بـه ديابـت عبارتند از: كاهش عملكرد اجتماعى و كيفيت زندگى بيمار، كـاهش فعاليتهاى حركتى و احتمالاً افززايش جــاقى، كـاهش يايبنــى بــه رزيمدرمانى، افزايش بروز رفتارهاى ناسالم مانند مصـرف سـيخار و

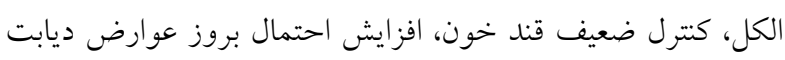
به سبب كنترل نامناسب قنــ خـون. همراهـى ايسن دو نـوع مشـكل موجب ايجاد مشكلات بسيار و تحميل هزينههاى سنخين بر سيستم بهداشتى مى كردد. افسردكى علت اصلى ناتوانى در سراسر دنيا محسوب مىشود و رتبه جهارم را ازنظر بار جهانى بيمارىها و بـهـتنهايى بـزرگتسرين

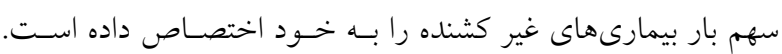
افسردگى ازجمله اختلالات خلقى است كه سـلامت روان را دجهـار

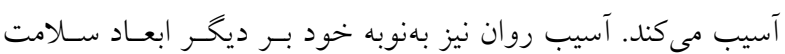

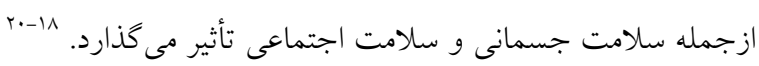

ديابت يكى از شايعتـرين بيمـارىهـاى انــدوكرين اسـت. ايسن بيمارى مزمن كه به دليل عدم ترشح كافى انسولين و يا عدم توانايى

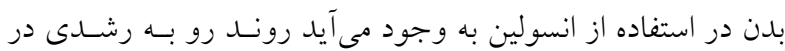

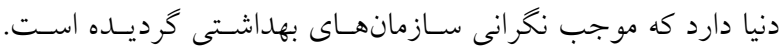

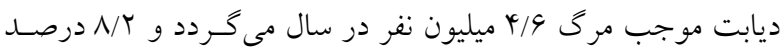

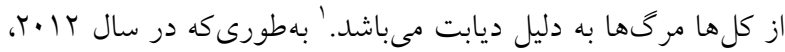

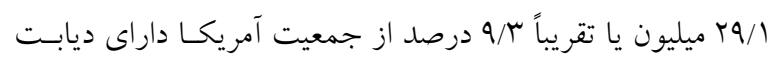
بودند كه از اين تعداد، ال ميليون تشخيص دادهشده و N/1 ميليـون

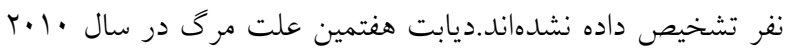

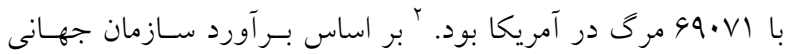
بهداشت در سال •r.r.r. ميلادى، تعداد موارد ابتلا به حدود دو برابـر

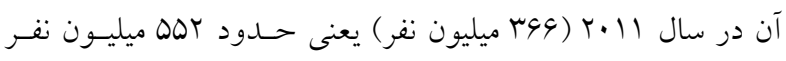

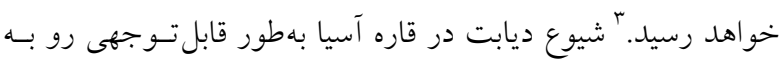

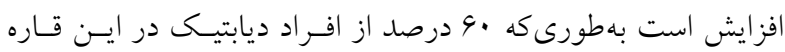

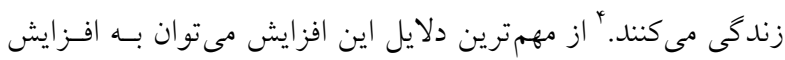
جمعيت و همينطور به بير شدن جمعيت در كنار تغيير الخو و شيوه زند اشى اشاره كرد.

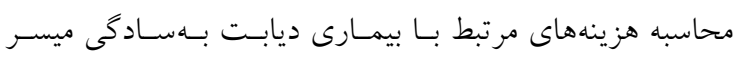
نيست ولى بعضى از برآوردها حساكى از آن اسـت كـه بساب ميليـارد

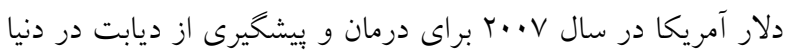
صرف شده است كه بيشبينى مىشود اين مبلغ بـه . .ب ميليـارد در

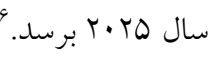
بيمارى ديابت به جنا دسته تقسيم مىشود. ديابت نوع يك، كـه

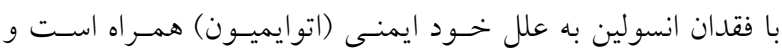

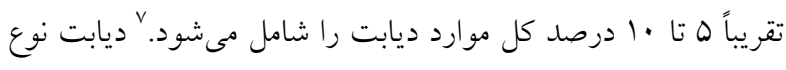
r كه با مقاومت به انسولين و فقدان نسبى آن مشـخص مسىشـود و

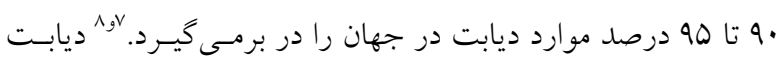
باردارى كه با شروع يا شناسايى ديابت طـى بـاردارى (بــراى اولـين

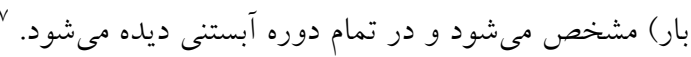

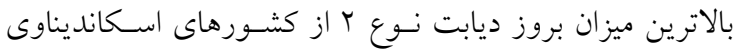

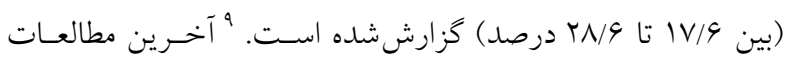
نشان داده كه V/A درصد از جمعيت هT تا •و ساله در كشور ايسران 
افسردگى را جزء طبيعى بيمارى ديابت مى دانند تشـخيص و درمـان

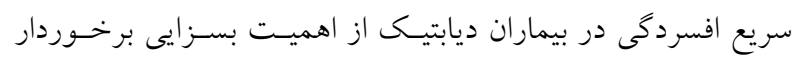

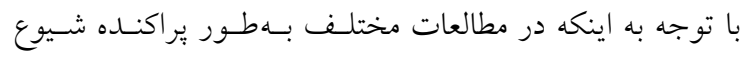

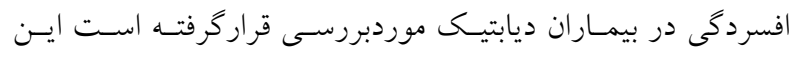

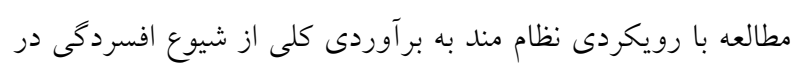

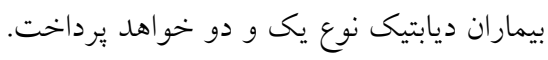

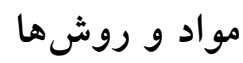

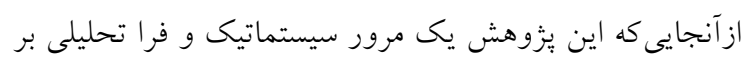

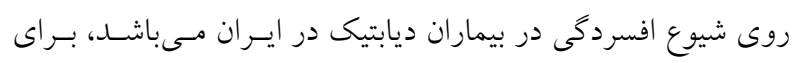

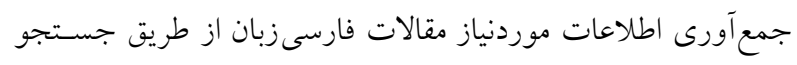

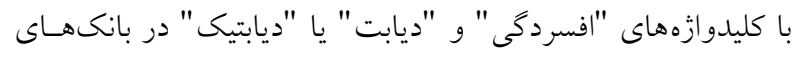

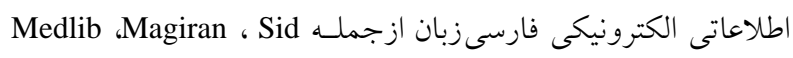

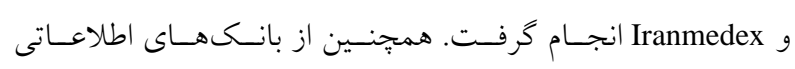

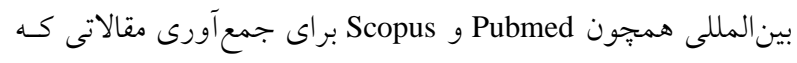

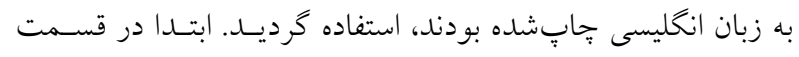

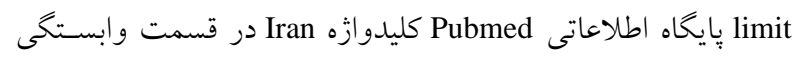

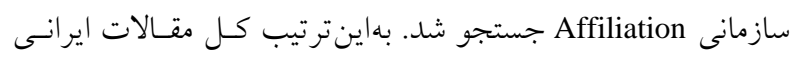

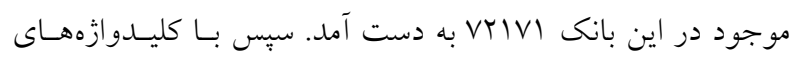

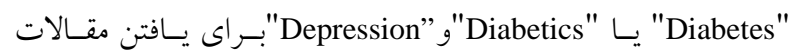

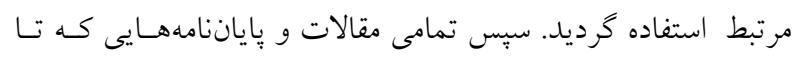

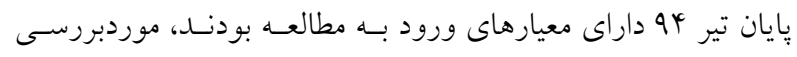

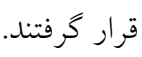

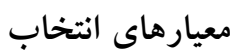

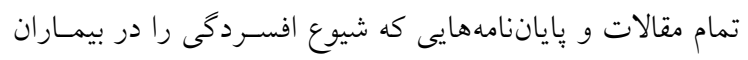

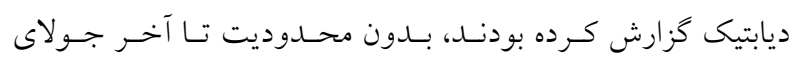

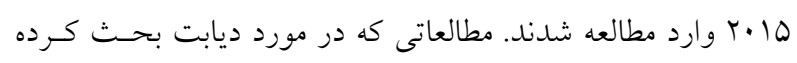

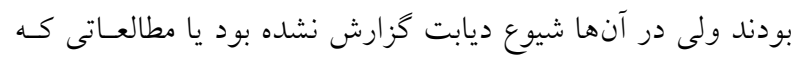

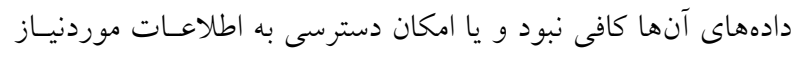

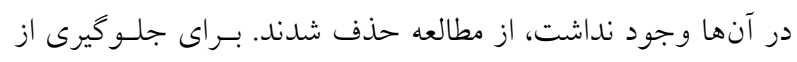

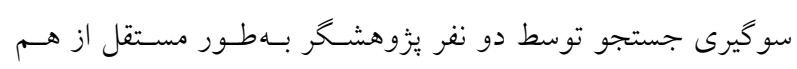

ميـزان افسـردكى در بيمـاران مبـتلا بـه ديابـت بيشـتر از سـاير

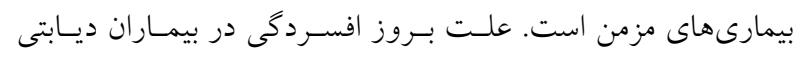

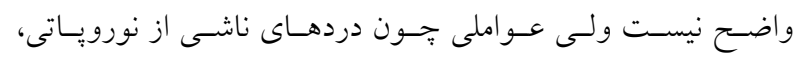

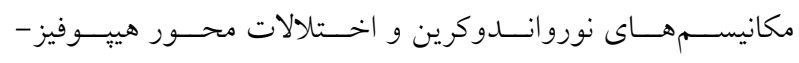

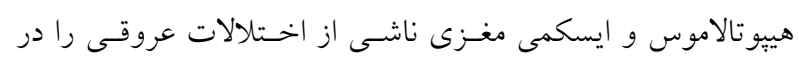

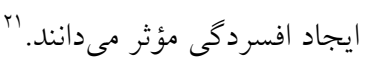

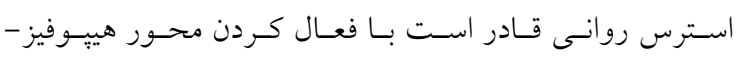

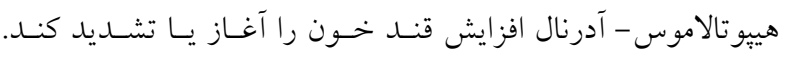

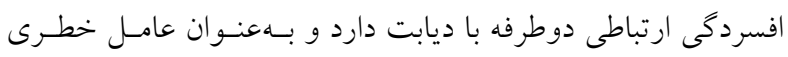

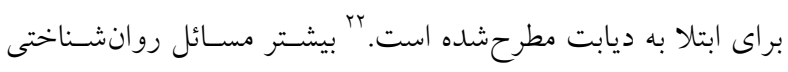

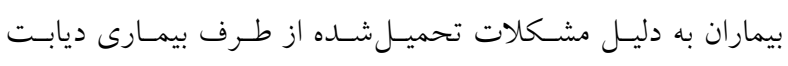

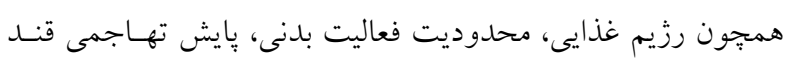

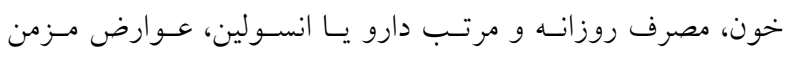

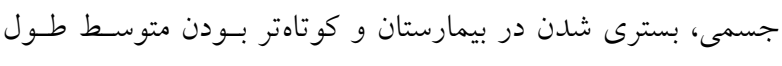
عمر مى باشد. بيماران ديابتى نياز به كنترل مداوم قند خون و عوارض ناشى از

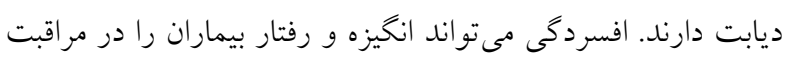

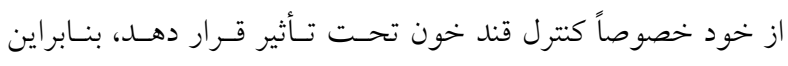

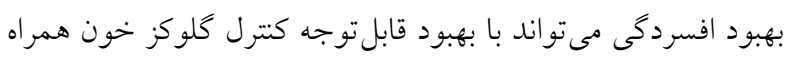

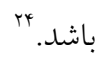

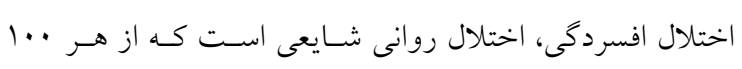

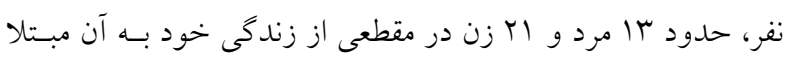

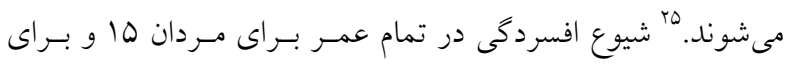

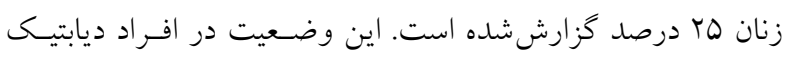

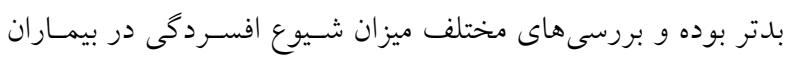

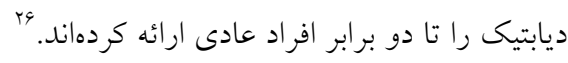

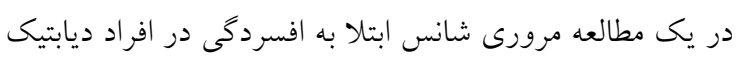

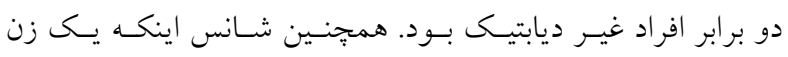

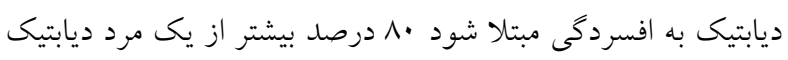

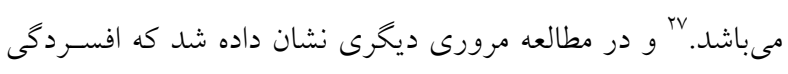

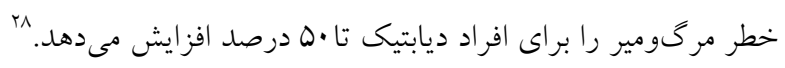

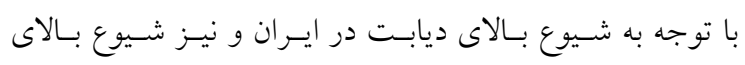

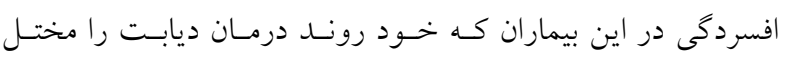

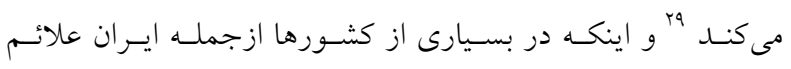




\section{يافتها}

در هر مطالعه شيوع افسردگى بهصورت توزيـع دوجملـهاى در

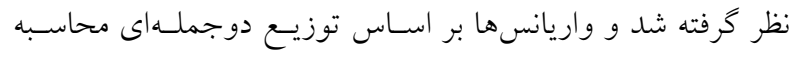

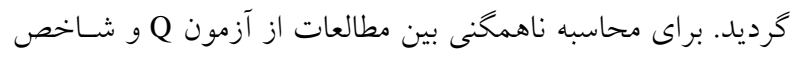

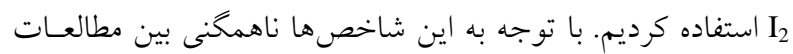

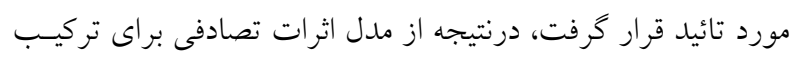

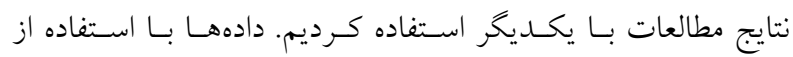

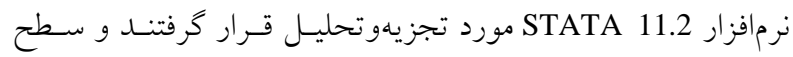
معنى دارى ه• إ• در نظر كرفته شد.

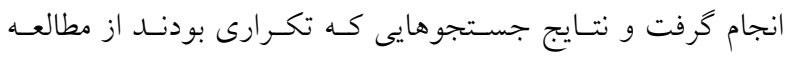

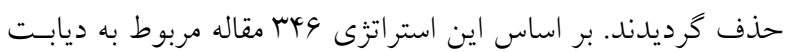

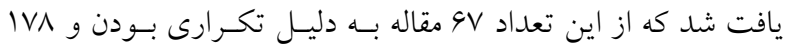

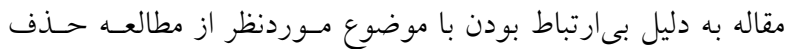

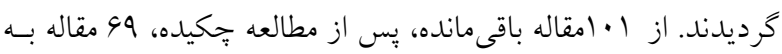

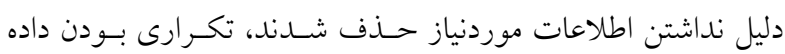

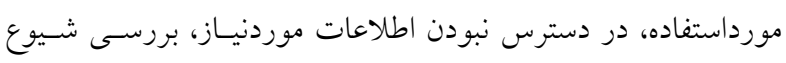

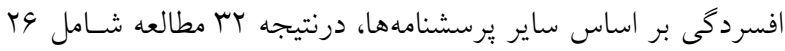

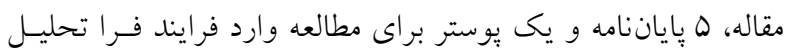

شدند (شكل ().

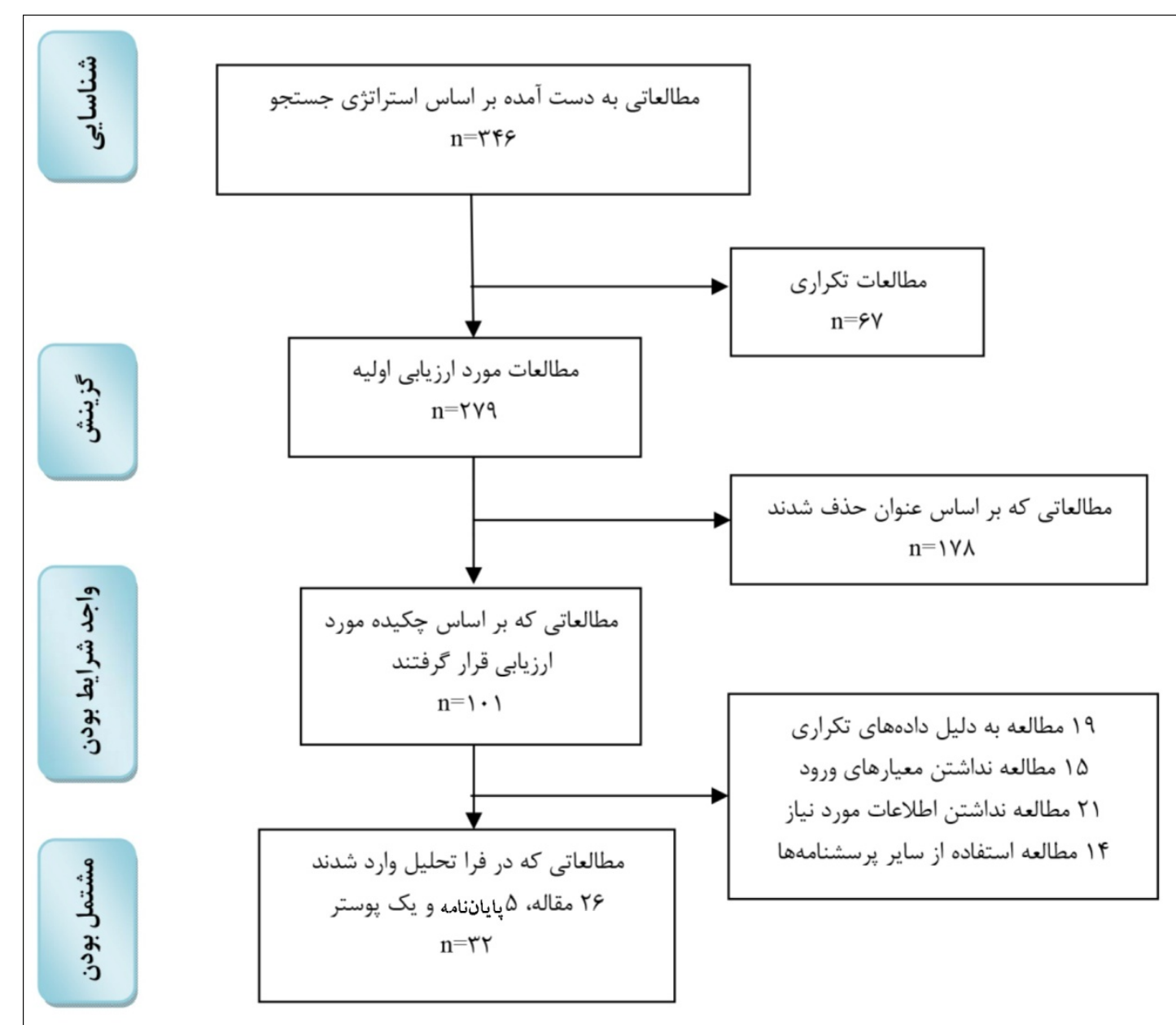

شكل 1: فرايند انتخاب مطالعات در مرور نظاممند و فرا تحليل 
موجود در ميزانهاى شيوع در مطالعات مختلـف از روش تصـادفى براى برآورد شيوع افسردكى در بيمار ان ديابتيك استفاده كرديم.

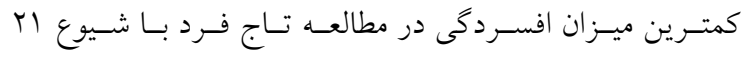

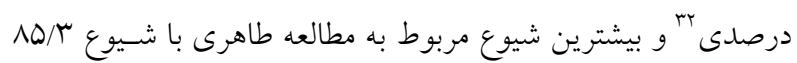

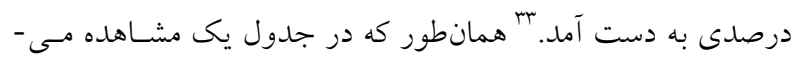

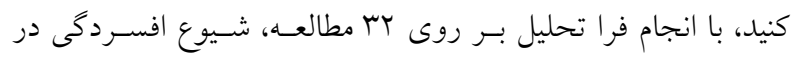

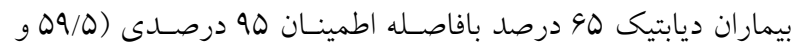

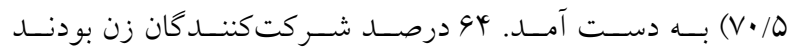

در צY مطالعه شيوع ديابت به تفكيك جنس دادهشده بود كه بـا

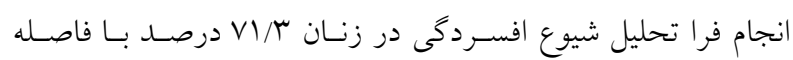

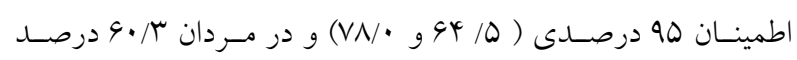

بافاصله اطمينان ( (

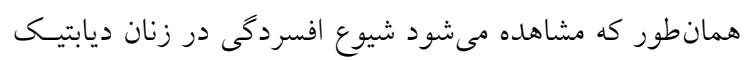

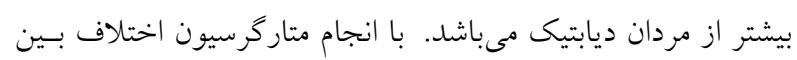

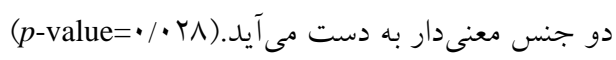

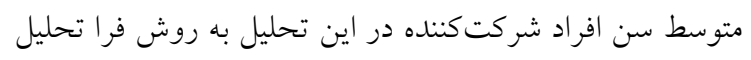

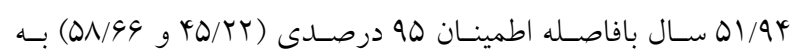

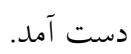

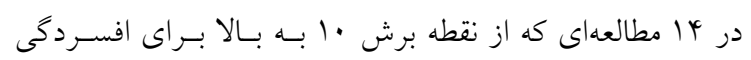

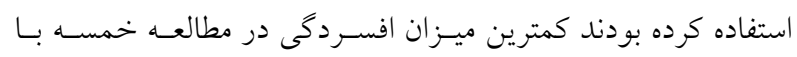

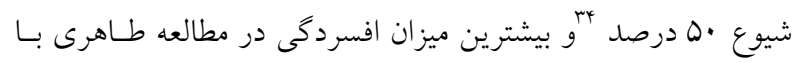
(ش
در بيشتر مقالاتى كه شيوع افسردكى را كزارش كـرده بودنــــ از

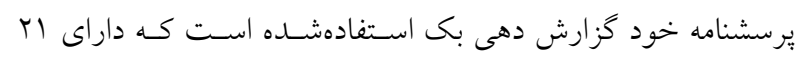
سؤال مىباشد. كمترين امتياز بر اساس اين مقياس صفر و بيشـترين

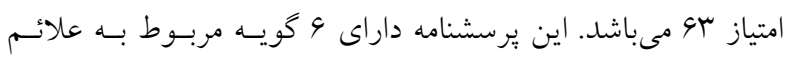
جسمانى و با كويه مربوط به علائم شناختى است. هرجقاندر امتيـاز

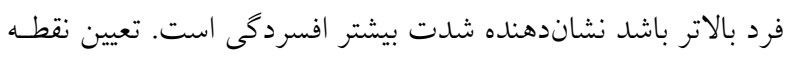

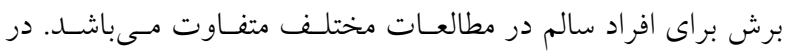

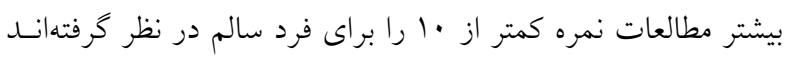

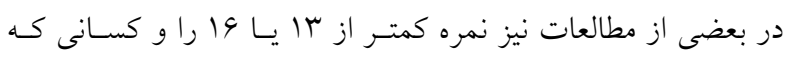

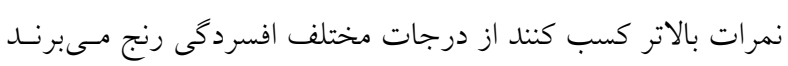

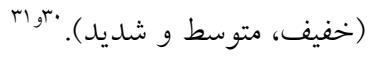

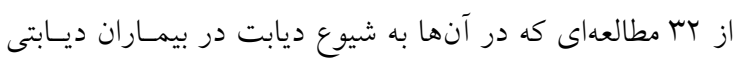

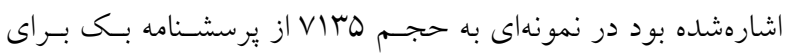

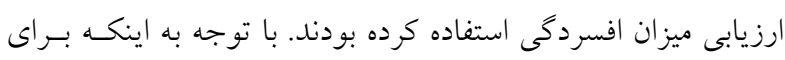

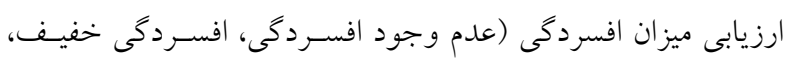

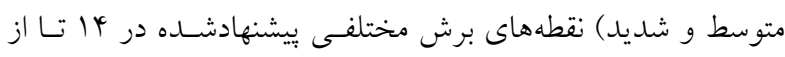

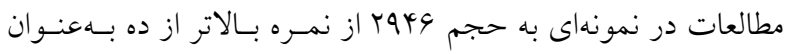

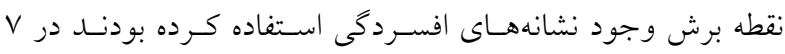

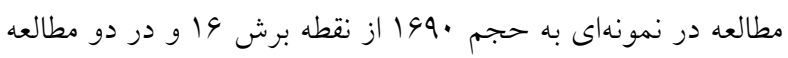

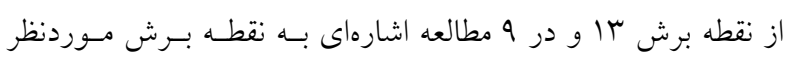

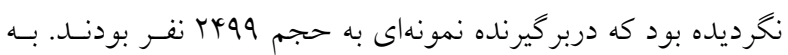

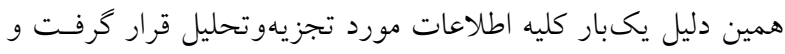

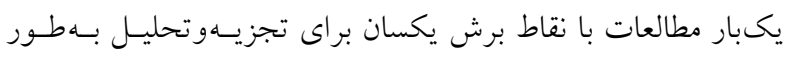

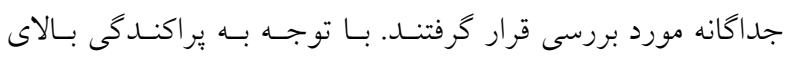

جدول ا: شيوع افسردگى با نقاط برش مختلف در فرا تحليل

\begin{tabular}{|c|c|c|c|c|c|c|}
\hline & تعداد مطالعات & حجم نمونه & شيوع افسردگى & فاصله اطمينان9ه٪ & مينيمم & ل اكزيمم \\
\hline كل مطالعات & rr & VIro & 90 & $V \cdot / \Delta-\Delta q / \Delta$ & YI & $\wedge Q / r$ \\
\hline بيشتر از ·1 & 14 & raks & $V M / 1$ & $V Q / V-99 / 0$ & 0. & $\Lambda \Delta / r$ \\
\hline بيشتر از 19 & $v$ & 199. & $r Q / 9$ & $\Delta Q-r \Delta / 1$ & rI & 94 \\
\hline بدون نقطه برش مشخص يا & 11 & $r \times 99$ & $v \cdot / 1$ & $9 Y / 9-V V / 0$ & $41 / 1$ & $\Delta * / Q$ \\
\hline
\end{tabular}




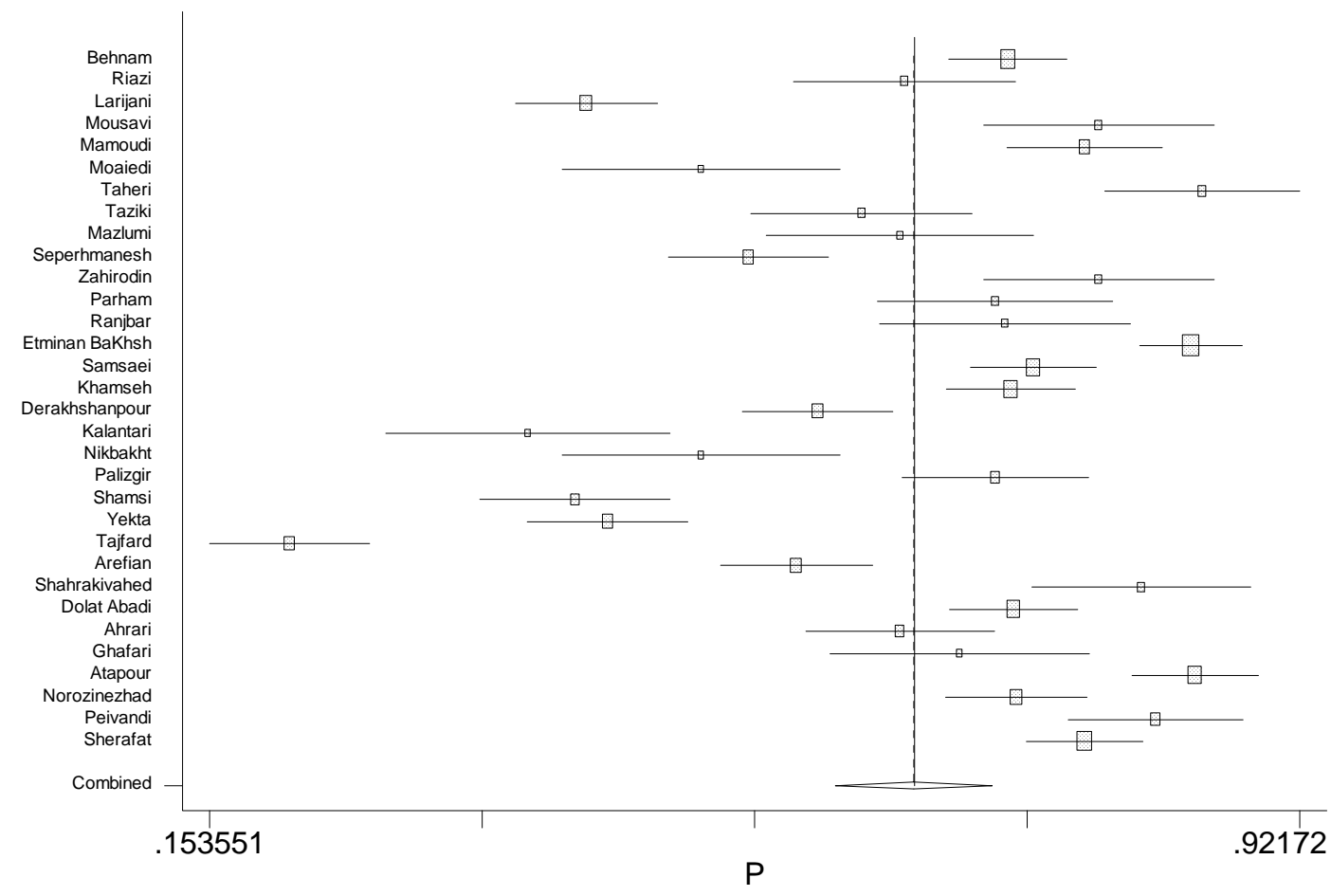

شكل r: شيوع افسردگى در بrم مطالعه در فرا تحليل

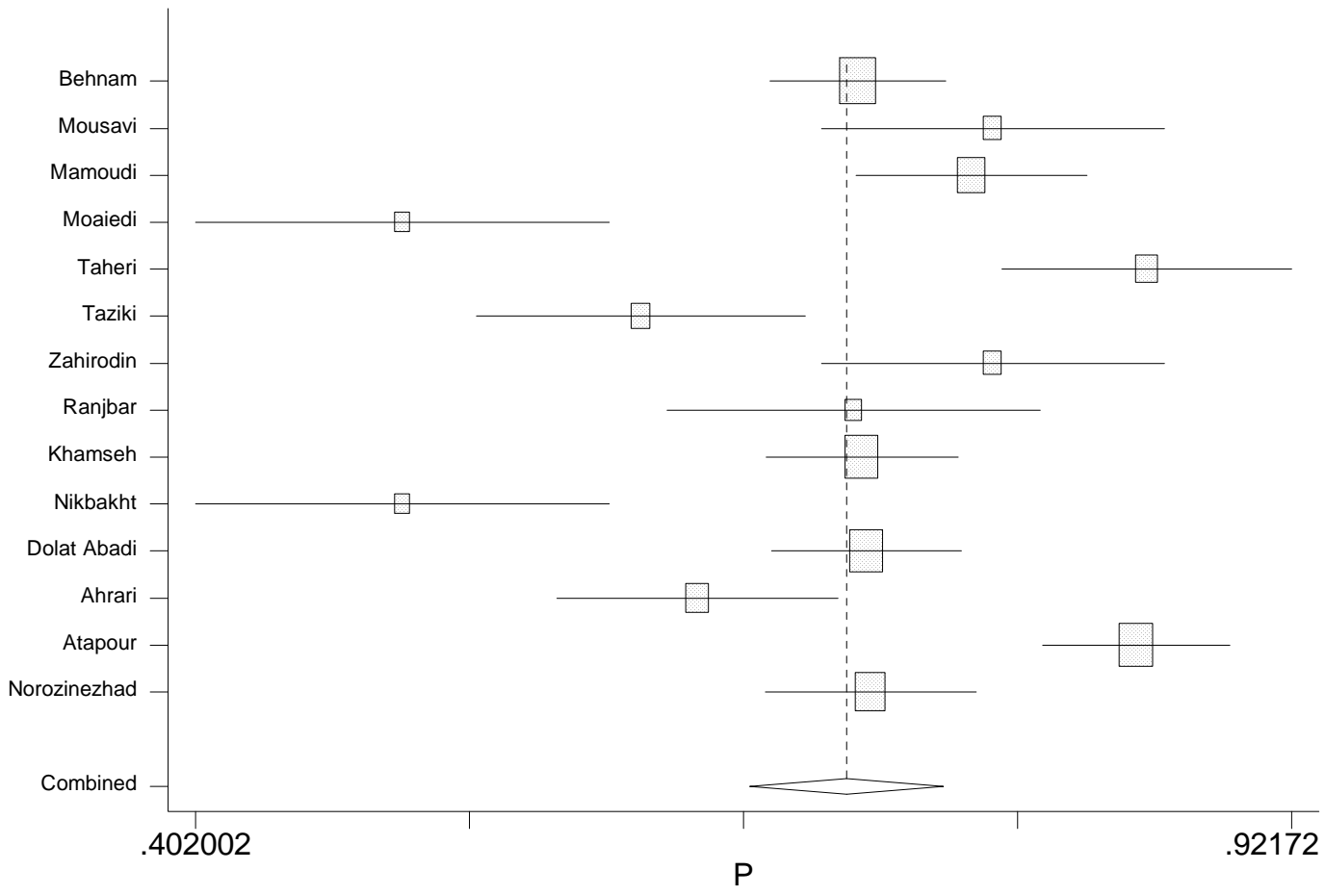

شكل r: شيوع افسردگى در \& أمطالعه با نقطه برش بالاتر از ده در فرا تحليل 


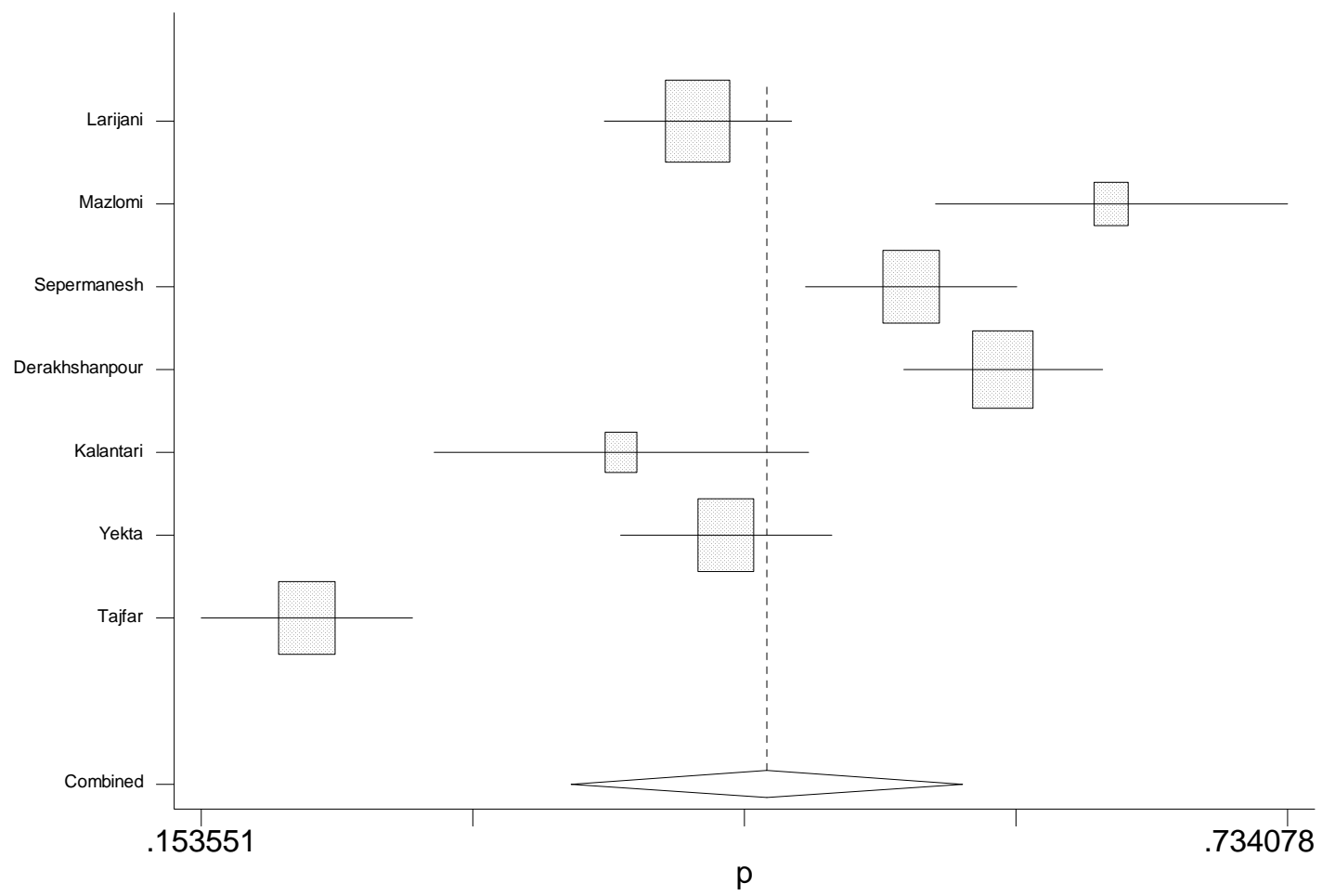

شكل fا: شيوع افسردكى در V مطالعه با نقطه برش بالاتر از شانزده در فرا تحليل

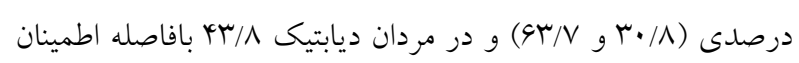
90 جنس اختلاف معنىدارى وجود ندارد. (p-value=•/V)

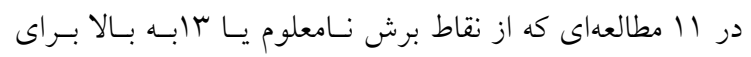

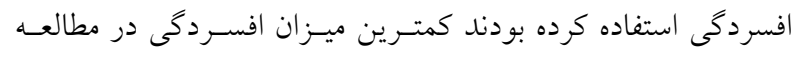

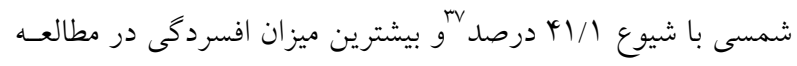

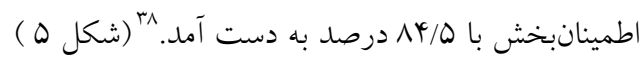

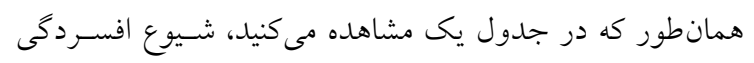

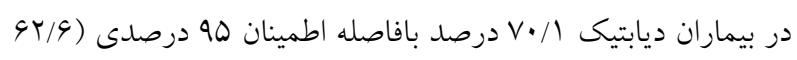
و (VV/D) به دست آمد. سو درصد شركت كنند كان زن بودند و شسيوع

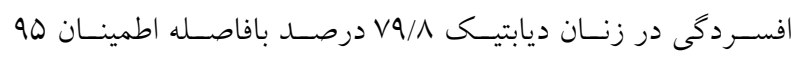

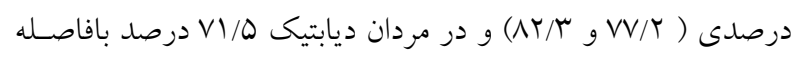

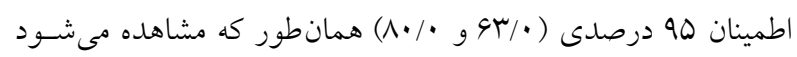
بين دو جنس اختلاف معنى دارى وجود ندارد (10)=-value).
همانطور كه در جدول يك مشاهده مىكنيد، شـيوع افسـردگى

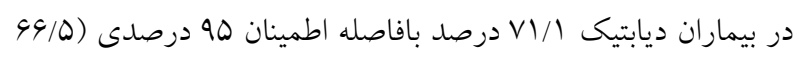

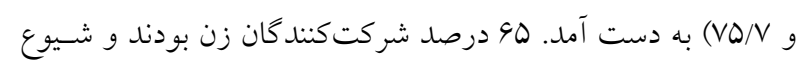

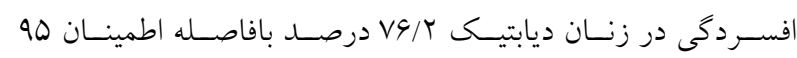

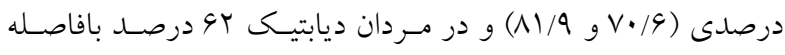

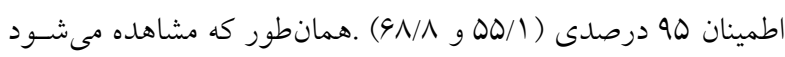

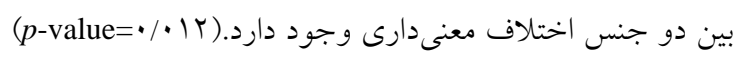

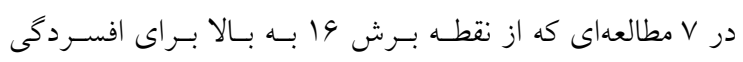

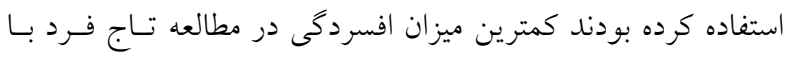

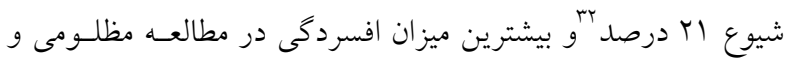
جعفرى با بو درصد به دست آمد.

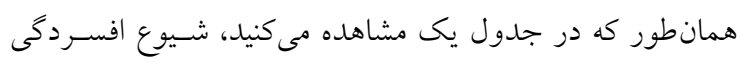

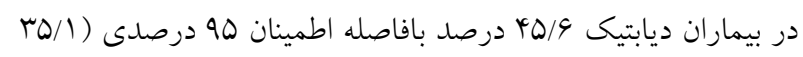

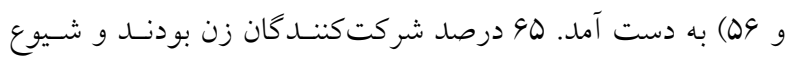

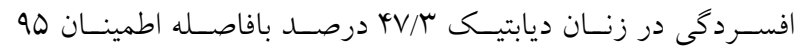




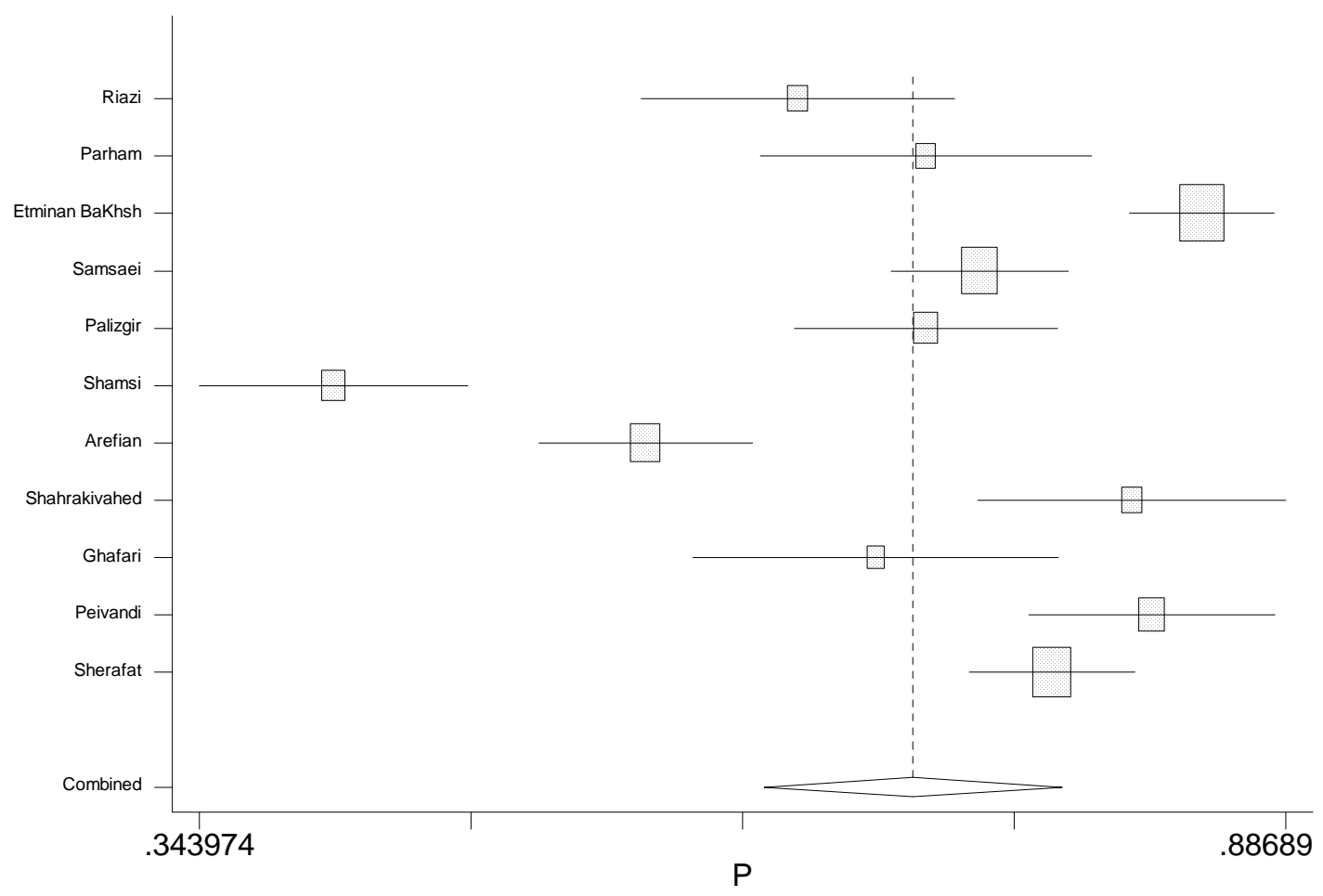

شكل ه: شيوع افسردكى در ا امطالعه با نقطه برش نامعلوم يا سا در فرا تحليل

بافاصله اطمينان ( ( )

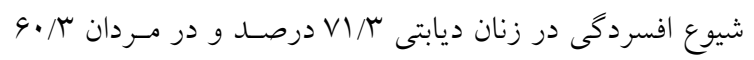

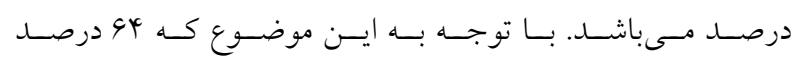

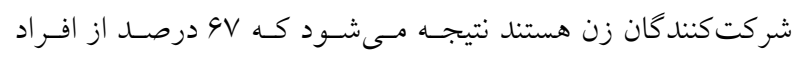
ديابتيك افسرده زن هستند و اين نشاندهنده اين وضعيت است كـه در مقابل هر يك مرد افسرده ديابتيك دو زن افسرده ديابتيك داريـم.

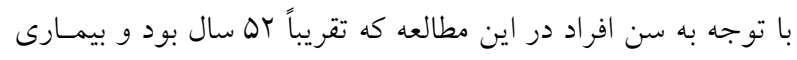

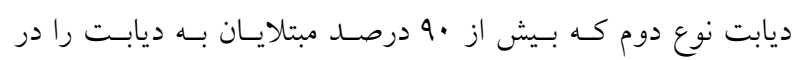
برمى گيرد از بيمارىهايى است كه در ميانسالى شروع مى دود و و در اين سن زنان با مشكلات هورمونى مربوط بـهـ يائسـحى نيـز دركيـر

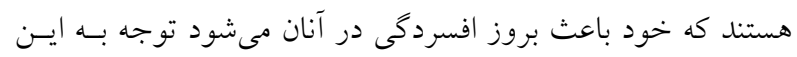
كروه از افراد جامعه ضرورى است. در يك مطالعه مرورى انجامشده در ايران شيوع ديابت در زنـان

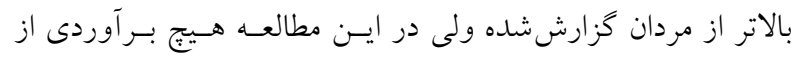
شيوع افسردكى داده نشــده ـ همجنـين اشـارهاى بـه تعـداد مقـالات

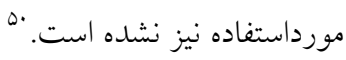
افسردگى بيمارى روحى است كه در ايسران شـيوع بـالايى دارد.

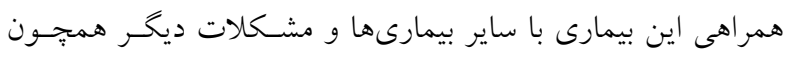

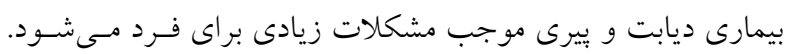

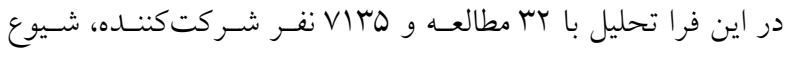
افسردكى در بيماران ديابتيك نوع يك و دو له 90 درصد به دست آمد. در يك مطالعه فرا تحليل كه دربر گيرنــد ب ب مطالعسه مختلـف بـود

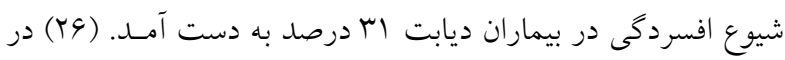
مطالعهاى در يونان شيوع افسردكى در بيماران \&ه، هند الغ ، بحسئرين

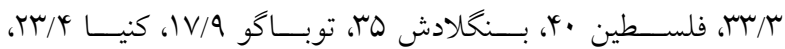

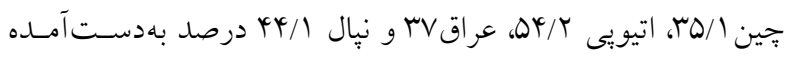

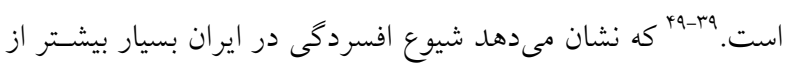
ساير كشورها(جهه همسايه و جّه غير همسايه) مىباشد.

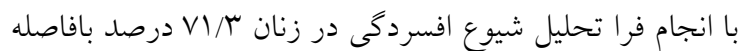

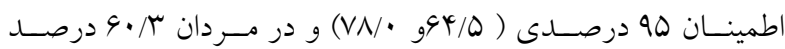


كه ما فقط مقالاتى را كه به زبان فارسى يا انگليسى بود موردبررسى

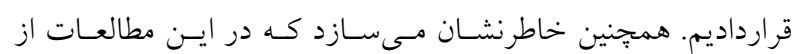

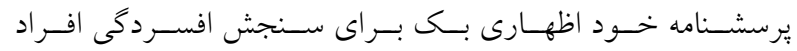

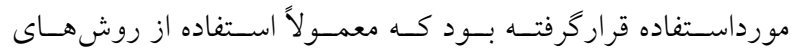
يرسشنامهاى موجب بيش بــر آوردى مسى شـود. همجنـين اطلاعـات

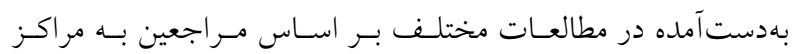

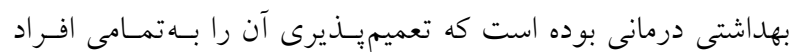
جامعه با مشكل مواجه مى سازد.

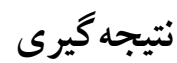

به نظر مىرسد كه در مراجعه بيمـاران در درمـان بيمـارىهـاى

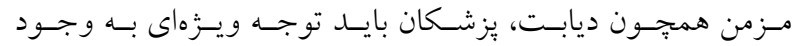
بيمارىهاى روحى آنان همتجون افسردگى داشته باشند و عـلاوه بـر كتترل نشانهاى جسمى بيمارى، نشانهاى روحى بيمـار را نيـز در نظر داشته باشند. درمان همزمـان بيمـارى جسـمى و روحسى بيمـار

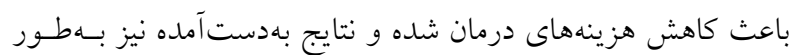
قابل توجهى بهتر خواهد بود.

\section{References}

1. Guariguata L, Whiting D, Weil C, Unwin N. The International Diabetes Federation diabetes atlas methodology for estimating global and national prevalence of diabetes in adults. Diabetes research and clinical practice 2011;94(3):322-32.

2. Control CfD, Prevention. National diabetes statistics report: estimates of diabetes and its burden in the United States, 2014. Atlanta, ga: US Department of health and human services. 2014

3.Whiting DR, Guariguata L, Weil C, Shaw J. IDF diabetes atlas: global estimates of the prevalence of diabetes for 2011 and 2030. Diabetes research and clinical practice 2011;94(3):311-21.

4.Chan JC, Malik V, Jia W, Kadowaki T, Yajnik CS, Yoon $\mathrm{K}-\mathrm{H}$, et al. Diabetes in Asia: epidemiology, risk factors, and pathophysiology. Jama 2009;301(20):2129-40.

5. Maddah M, Rashidi A, Mohammadpour B, Vafa R, Karandish M. In-school snacking, breakfast consumption, and sleeping patterns of normal and overweight Iranian

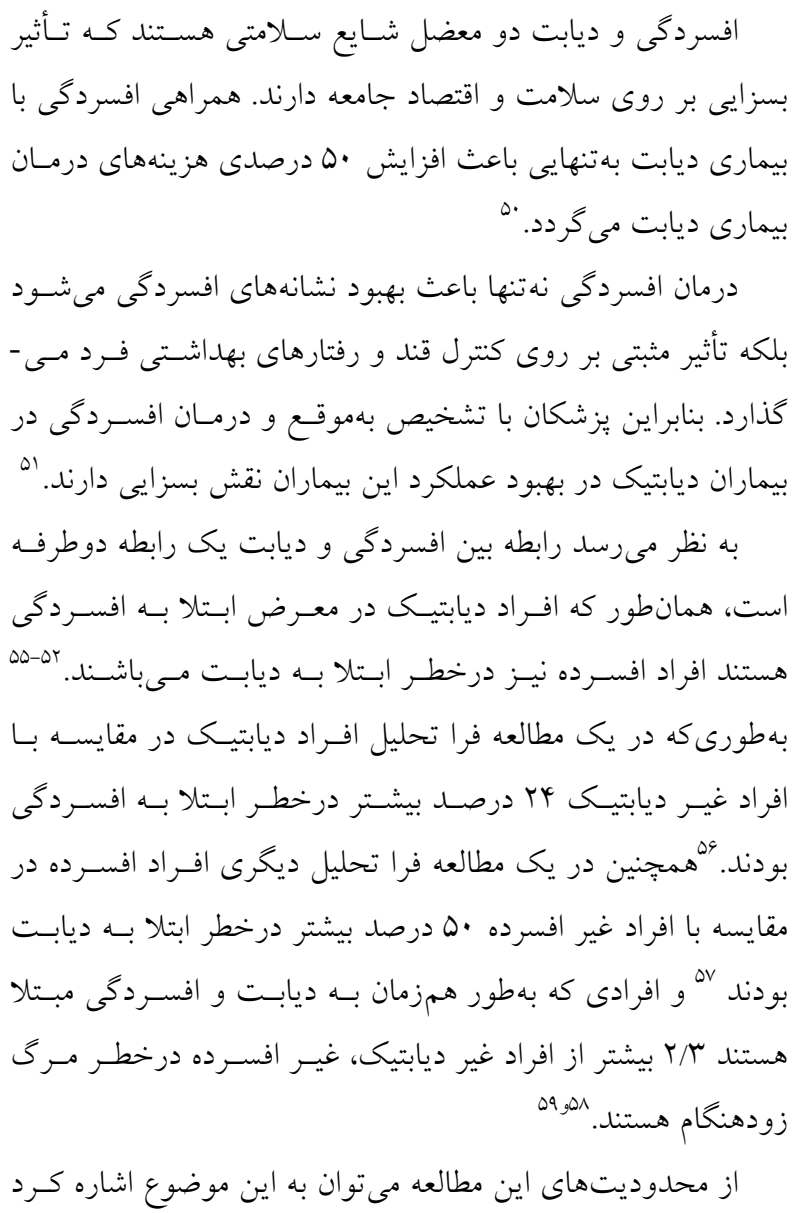

high school girls: a study in urban and rural areas in Guilan, Iran. Journal of nutrition education and behavior 2009;41(1):27-31.[In Persian]

6. Shankhdhar K, Shankhdhar LK, Shankhdhar U, Shankhdhar S. Diabetic foot problems in India: an overview and potential simple approaches in a developing country. Current diabetes reports 2008;8(6):452-7.

7. Harris M. Definition and classification of diabetes mellitus and the criteria for diagnosis. Leroith D, Olesky JM, Taylor SI Diabetes mellitus: a fundamental and clinical text 3rd ed Philadelphia: Lippincott Williams \& Wilkins. 2004:457-61.

8. Bergenstal R, Kendall D, Franz M, Rubenstein A. Management of type 2 diabetes: a systematic approach to meeting the standards of care. II: Oral agents, insulin, and management of complications. Endocrinology 4th ed Philadelphia, Pa: WB Saunders Co. 2001:822.

9. Larejani B, Zahedi F. Epidemiology of diabetes mellitus in Iran. Iranian Journal of Diabetes and Metabolism 2001; 1 (1) :1-8. [In Persian] 
10. International Diabetes Prevention and Control Foundation http://www.idpcf.com/Default.aspx?PageId=3aZmYag4. [In Persian]

11. Haghdoost A, Rezazadeh Kermani M, Sadghirad B, Baradaran H. Prevalence of type 2 diabetes in the Islamic Republic of Iran: systematic review and meta-analysis. East Mediterr Health J. 2009;15(3):591-9. [In Persian]

12. Greden JF. Physical symptoms of depression: unmet needs. Journal of Clinical Psychiatry 2003;64:5-11.

13. Organization WH. Revised global burden of disease (GBD) 2002 estimates. Estimates by WHO Region and Sub-region Disability adjusted life years (DALY). 2005. http://www.who.int/healthinfo/bodgbd2002revised/en/

14. Üstün T, Ayuso-Mateos JL, Chatterji S, Mathers C, Murray CJ. Global burden of depressive disorders in the year 2000. The British journal of psychiatry 2004;184(5):386-92.

15. Delavari A, Mahdavi Hazaveh A, Norozivezhad A, Yarahmadi SH. National program for prevention and control of diabetes. 2009.

16. Bennett P. Epidemiology of type 2 diabetes mellitus. LeRoith D, taylor SI, Olefsky JM. Diabetes mellitus ,A fundamental and clinical text. 2000:544-48.

17. Olefsky JM, Kruszynska YT. Type 2 diabetes mellitus: etiology, pathogenesis and natural history. In: DeGroot LJ, Jameson JL. Endocrinology. Philadelphia: WB Saunders; 2001: 776-97.

18. Goldney RD, Phillips PJ, Fisher LJ, Wilson DH. Diabetes, depression, and quality of life a population study. Diabetes care 2004;27(5):1066-70.

19. Lin EH, Katon W, Von Korff M, Rutter C, Simon GE, Oliver M, et al. Relationship of depression and diabetes self-care, medication adherence, and preventive care. Diabetes care 2004;27(9):2154-60.

20. Ciechanowski PS, Katon WJ, Russo JE. Depression and diabetes: impact of depressive symptoms on adherence, function, and costs. Archives of internal medicine 2000;160(21):3278-85.

21. Halgin RP, Krauss Whitbourne S. Abnormal psychology: clinical perspectives on psychological disorders. 6th ed. New York, NY: McGraw Hill Company; 2010. p. 250. [In Persian].

22. Miri M, Abdorrazzaghnezhad M, HajiAbadi M, Soorgi Z, Qasemi K. Relationship between depression and level of reliance on God in Birjand university students. Moraghebat hay novin 2008; 14(4): 9-15. [In Persian].

23. Sridhar GR. Psychiatric co-morbidity \& diabetes. Indian J Med Res. 2007: 125(3): 311-20.

24. Koopmanschap M. Coping with Type II diabetes: the patient's perspective. Diabetologia 2002;45(7): 18-S22.
25- Lustman Pj, Skor DA, Careny RM, Staniago JV,Cryer PE. Stress And diabetic Control. 1983:4:526-88

26.Anderson RJ, Freedland KE, Clouse RE, Lustman PJ. The prevalence of comorbid depression in adults with diabetes a meta-analysis. Diabetes care 2001;24(6):1069-78.

27.Park M, Katon WJ, Wolf FM. Depression and risk of mortality in individuals with diabetes: a meta-analysis and systematic review. General hospital psychiatry 2013;35(3):217-25.

28- Abasalli Zadeh A, Asadollah AH. Answer to common patient's questions about depression. 1379: 13. [In Persian].

29. Gelder M. Oxford text book of psychiatry. 3rd ed. Oxford: medical publication psychiatry.1995

30. Beck A, Rush J. Cognitive therapy of depression. New York: Gilford Press; 2000. p. 13-15.

31.Kaviani H, Mousavi A. Psychometric properties of the Persian version of Beck Anxiety Inventory (BAI). Tehran University Medical Journal. 2008;66(2):136-40. [In Persian]

32. Tajfard M, Mobarhan MG, Rahimi HR, Mouhebati M, Esmaeily H, Ferns GA, et al. Anxiety, Depression, Coronary Artery Disease and Diabetes Mellitus; An Association Study in Ghaem Hospital, Iran. Iranian Red Crescent Medical Journal 2014;16(9). [In Persian]

33. Taheri N1 etal . The Survey of Anxiety and Depression Prevalence in Diabetic Patient Referred to Abadan Taleghani and Khorramshahr Valiasr Hospitals in 2011. JOURNAL OF DIABETES NURSING 2014 ; 1(2) [In Persian].

34. Khamseh ME, Baradaran HR, Rajabali H. Depression and diabetes in Iranian patients: a comparative study. The International Journal of Psychiatry in Medicine 2007;37(1):81-6. [In Persian].

35. Mazloomy S, Mirzaei A, Mohammadi S. Study of depression prevalence in the patients with type II diabetes referring to Yazd diabetes research centers in 2008. TOLOO-E-BEHDASHT 2008 ; 7 (23-24):30 - 35.[In Persian]

36. Ghaffari M, Shahbazian H, Kholghi M, Haghdoost M. Relationship between social support and depression in diabetic patients. Jundishapur Scientific Medical Journal 2010;8(4):384-9. [In Persian]

37. Shamsi A, Khodaifar F, Arzaghi SM, Sarvghadi F, Ghazi A. Is there any relationship between medication compliance and affective temperaments in patients with type 2 diabetes? Journal of Diabetes \& Metabolic Disorders 2014;13(1):96. [In Persian]

38. Etminanbakhsh. H, Abedini. N, Etminanbakhsh M, Shaehvin A. Comparison frequency and sever depression among diabetic patients. Poster. [In Persian] 
39. Raval A, Dhanaraj E, Bhansali A, Grover S, Tiwari P. Prevalence \& determinants of depression in type 2 diabetes patients in a tertiary care centre. Indian J Med Res. 2010;132:195-200.

40. Nasser J, Habib F, Hasan M, Khalil N. Prevalence of depression among people with diabetes attending diabetes clinics at primary health settings. Bahrain Med Bull. 2009;31:1-7. [In Persian]

41. Sweileh WM, Abu-Hadeed HM. Prevalence of depression among people with type 2 diabetes mellitus: a cross sectional study in Palestine. BMC public health 2014;14(1):163.

42. Roy T, Lloyd CE, Parvin M, Mohiuddin KGB, Rahman $\mathrm{M}$. Prevalence of co-morbid depression in out-patients with type 2 diabetes mellitus in Bangladesh. BMC psychiatry 2012;12(1):123.

43. Frederick F, Maharajh H. Prevalence of depression in type 2 diabetic patients in Trinidad and Tobago. The West Indian medical journal 2013;62(7):628-31.

44. Poongothai S, Anjana RM, Pradeepa R, Ganesan A, Unnikrishnan R, Rema $M$, et al. Association of depression with complications of type 2 diabetes-The Chennai Urban Rural Epidemiology Study (CURES-102). Journal of Association of Physicians of India 2011;59:640-4.

45. Wang L, Song R, Chen Z, Wang J, Ling F. Prevalence of depressive symptoms and factors associated with it in type 2 diabetic patients: a cross-sectional study in China. BMC public health 2015;15(1):188.

46. Dejenie Habtewold T, Radie YT, Sharew NT. Prevalence of Depression among Type 2 Diabetic Outpatients in Black Lion General Specialized Hospital, Addis Ababa, Ethiopia. Depression research and treatment 2015.

47. Yousif KH, Farhood HF. Evaluation of the risk factors for the development of metabolic syndrome in Babylon 2012. Journal of Natural Sciences Research 2013;3(6):116-31. [In Persian]

48. Joshi S, Dhungana RR, Subba UK. Illness Perception and Depressive Symptoms among Persons with Type 2 Diabetes Mellitus: An Analytical Cross-Sectional Study in Clinical Settings in Nepal. Journal of diabetes research 2015.
49.Izadi tameh A, Naderi Far M2, Naderi Far A, Nikbakht R. Depression in patients with Diabetes: A Review Article.2005. [In Persian]

50. Egede LE. Effect of depression on self-management behaviors and health outcomes in adults with type 2 diabetes. Current Diabetes Reviews 2005;1(3):235-43.

51. De Groot M, Doyle T, Hockman E, Wheeler C, Pinkerman B, Shubrook J, et al. Depression among type 2 diabetes rural Appalachian clinic attendees. Diabetes care 2007;30(6):1602-4.

52. Renn BN, Feliciano L, Segal DL. The bidirectional relationship of depression and diabetes: a systematic review. Clinical psychology review 2011;31(8):1239-46.

53. Katon WJ. Epidemiology and treatment of depression in patients with chronic medical illness. Dialogues in clinical neuroscience 2011;13(1):7.

54. De Groot M, Anderson R, Freedland KE, Clouse RE, Lustman PJ. Association of depression and diabetes complications: a meta-analysis. Psychosomatic medicine 2001;63(4):619-30.

55. Dirmaier J, Watzke B, Koch U, Schulz H, Lehnert H, Pieper L, et al. Diabetes in primary care: prospective associations between depression, nonadherence and glycemic control. Psychotherapy and psychosomatics 2010;79(3):172-8.

56. Nouwen A, Winkley K, Twisk J, Lloyd C, Peyrot M, Ismail $\mathrm{K}$, et al. Type 2 diabetes mellitus as a risk factor for the onset of depression: a systematic review and metaanalysis. Diabetologia 2010;53(12):2480-6.

57. Rotella F, Mannucci E. Depression as a risk factor for diabetes: a meta-analysis of longitudinal studies. The Journal of clinical psychiatry 2013;74(1):31-7.

58. Fisher EB, Brownson CA, O'Toole ML, Shetty G, Anwuri VV, Fazzone P, et al. The Robert Wood Johnson Foundation Diabetes Initiative Demonstration Projects Emphasizing Self-management. The Diabetes Educator 2007;33(1):83-94.

59. Katon W, Lyles CR, Parker MM, Karter AJ, Huang ES, Whitmer RA. Association of depression with increased risk of dementia in patients with type 2 diabetes: the Diabetes and Aging Study. Archives of general psychiatry 2012;69(4):410-7. 